\title{
Construction Risk Analysis of Subway Station Based on Bayesian Network
}

\author{
Shiwei Hou ${ }^{1, a^{*}}$, Xin Zhang ${ }^{1, b}$, Zhiguo Xin ${ }^{1, c}$ and Xueli Zhang ${ }^{1, d}$ \\ ${ }^{1}$ School of Civil Engineering, Shenyang Jianzhu University, Shenyang 110168, China; \\ ahsw1375@126.com, b102049610@qq.com, c2295253223@qq.com, d970557011@qq.com
}

\begin{abstract}
Keywords: Subway Station; Risk Analysis; Bayesian Network; Sensitivity Analysis
Abstract. The subway station construction risk factors of uncertainty is researched based on Bias network theory, the safety risk of metro station foundation is analyzed taking a metro station in Shenyang as an example. The possible risk factors for the construction process of subway station was collected combined with the actual engineering situation. The risk factors to establish a priori probability parameters Bayesian network model is constructed, and operation analysis by forward reasoning Bayesian network model is presented. The results show that the overall probability level is III, the most sensitive risk factors for foundation is pit surrounding buildings settlement and displacement.
\end{abstract}

\section{Introduction}

In recent years, with the development of urban underground space, the application of new materials and new technologies, the scale and technology of subway construction have been developing rapidly. At the same time, because of the complexity of the process and the instability of the construction environment and other aspects of the various accidents also caused adverse effects and economic losses to the country, so how to determine the main risk factors and risk aversion have become an important subject of subway project risk research.

Domestic and foreign scholars have a lot of research foundation in the field of risk analysis, focusing on the identification and control of risk factors. Chen used fuzzy comprehensive evaluation method to assess the construction of subway station risk and determine the weight of the factors [1]. Zhao improved the traditional fault tree analysis method to build the subway construction safety risk a complete analysis system [2]. $\mathrm{Li}$ and $\mathrm{Du}$ etc. improved analytic hierarchy process applied in the construction of risk identification of excavation subway station and improve the accuracy of risk identification [3]. The above-mentioned risk analysis methods have a lot of deficiencies in the knowledge of uncertainties in complex situations. In recent years, the domestic geological construction accidents frequent, more people have a profound understanding of the current methods used for uncertainty reasoning should not meet the demand.

\section{Management system of subway risk}

Identification and Analysis of Subway Risk Factors. Firstly, the accident and the loss pattern of the subway station project are analyzed reasonably and the risk factors are analyzed. Secondly, the preliminary risk list is established and the main risk factors are determined by the Bayesian connection tree algorithm.

Establishment of Bayesian Network.In the Bayesian network structure, the nodes represent the risk factors or risk events at the construction stage. This type of node can be directly described by the probability of occurrence and the probability of occurrence. The state variables of each risk factor are 
the parameters that need to be determined in the two networks. The term is the probability distribution of the node, that is, the edge probability of the node and each node The conditional probability table. According to the specific network structure, according to the causal relationship between the variable and the independent dependency, the probability calculus can be calculated according to the data given by each node conditional probability table, and the edge probability of each node is obtained.

Reasoning Risk Prediction Based on Causality. Through the above content has been able to basically determine the subway construction risk assessment required for the Bayesian network structure. Then we can achieve the entire network probability of reasoning calculation. In this paper, the Bayesian network risk reasoning is divided into two parts: the positive reasoning and the sensitivity analysis based on causality. The positive reasoning is that in the case of a certain risk factor, The Bayesian network risk event occurs as a conditional probability. The set of nodes can be expressed as $\mathrm{O}=(\mathrm{X} 1, \mathrm{X} 2, \mathrm{X} 3 \ldots \mathrm{Xn})$, $\mathrm{n}$ represents the number of nodes, and $\mathrm{Y}$ is the state value of the risk event, then the probability of occurrence is $\mathrm{P}(\mathrm{S}=\mathrm{Y} \mid \mathrm{X})$ :

$$
\begin{array}{r}
\mathrm{P}=(\mathrm{S}=\mathrm{Y} \mid \mathrm{X})=\mathrm{P}\left(\mathrm{S}|\mathrm{Y}| \mathrm{X} 1=\mathrm{x}_{1}, \mathrm{X}_{2}=\mathrm{x}_{2}, \ldots, \mathrm{X}_{\mathrm{n}}=\mathrm{x}_{\mathrm{n}}\right) \\
=\mathrm{P}\left(\mathrm{S}=\mathrm{Y}, \mathrm{X}_{1}=\mathrm{x}_{1}, \mathrm{X}_{2}=\mathrm{x}_{2}, \ldots, \mathrm{X}_{\mathrm{n}}=\mathrm{x}_{\mathrm{n}}\right) / \mathrm{P}\left(\mathrm{X}_{1}=\mathrm{x}_{1}, \mathrm{X}_{2}=\mathrm{x}_{2}, \ldots, \mathrm{X}_{\mathrm{n}}=\mathrm{x}_{\mathrm{n}}\right)
\end{array}
$$

$\mathrm{P}\left(\mathrm{S}=\mathrm{Y}, \mathrm{X}_{1}=\mathrm{x}_{1}, \mathrm{X}_{2}=\mathrm{x}_{2}, \ldots, \mathrm{X}_{\mathrm{n}}=\mathrm{x}_{\mathrm{n}}\right)$ is the conditional probability of forwarding the Bayesian network forward, $\mathrm{P}\left(\mathrm{X}_{1}=\mathrm{x}_{1}, \mathrm{X}_{2}=\mathrm{X}_{2}, \ldots, \mathrm{X}_{\mathrm{n}}=\mathrm{X}_{\mathrm{n}}\right)$ represents the probability of a known state event, each node has two status values, $\mathrm{Y}$ and $\mathrm{N}$.

Sensitivity analysis. Sensitivity analysis is to analyze the sensitivity of the query node probability in the Bayesian network to the probabilistic change of the probability of the node. In the probability system, the entropy is the degree of uncertainty Common indicators.

\section{Risk Analysis of Metro Station Based on Bayesian Network}

The risk analysis is based on a subway station in Shenyang, the station has two underground digging station, subway station building length $284.0 \mathrm{~m}$, width $25.95 \mathrm{~m}$, construction area of $7369.8 \mathrm{~m}^{2}$, the overburden thickness of the station roof is $3.2 \mathrm{~m}$, underground buried depth of $16.7 \mathrm{~m}$.

Identification of risk factors. This paper summarizes the list of possible risk factors by combining the data collection and on-site expert interviews and discussion [4,5], as well as the construction of Shenyang local subway station [6], and then discuss the main risk factors through expert discussion. Table 1 lists the 15 major risk factors that affect the safety of subway construction in China. Combining with the literature, the bottom node conditional probability of each risk factor is obtained. Sub-grade construction risk level table in Table 2. 
Table.1 Risk factors and conditional probability table

\begin{tabular}{|c|c|c|c|c|}
\hline $\begin{array}{l}\text { Serial } \\
\text { number }\end{array}$ & Source of risk & Major risk factors & Code & $\begin{array}{l}\text { Bottom node } \\
\text { conditional } \\
\text { probability }\end{array}$ \\
\hline 1 & \multirow{5}{*}{$\begin{array}{c}\text { Excavation of } \\
\text { foundation pit } \\
(\mathrm{J}) \\
\text { Continuous wall } \\
\text { construction }(\mathrm{X})\end{array}$} & Collapsed & $\mathrm{J}_{1}$ & 0.45 \\
\hline 2 & & $\begin{array}{l}\text { Removal support order } \\
\text { reversed }\end{array}$ & $\mathrm{J}_{2}$ & 0.54 \\
\hline 3 & & Building settlement & $\mathrm{J}_{3}$ & 0.32 \\
\hline 4 & & Collapsed & $\mathrm{X}_{1}$ & 0.43 \\
\hline 5 & & Hoisting cage collapse & $\mathrm{X}_{2}$ & 0.64 \\
\hline 6 & \multirow{3}{*}{$\begin{array}{l}\text { Light rail } \\
\text { reinforcement } \\
\text { (H) }\end{array}$} & $\begin{array}{l}\text { Mechanical piercing } \\
\text { pier column, beam }\end{array}$ & $\mathrm{H}_{1}$ & 0.64 \\
\hline 7 & & $\begin{array}{l}\text { Excessive displacement } \\
\text { of pier }\end{array}$ & $\mathrm{H}_{2}$ & 0.43 \\
\hline 8 & & $\begin{array}{l}\text { Light rail orbit uneven } \\
\text { settlement }\end{array}$ & $\mathrm{H}_{3}$ & 0.54 \\
\hline 9 & \multirow{5}{*}{$\begin{array}{l}\text { Weidang scene } \\
\text { (Y) } \\
\text { Grouting } \\
\text { construction } \\
\text { (E) }\end{array}$} & pipeline rupture & $\mathrm{Y}_{1}$ & 0.44 \\
\hline 10 & & fence instability & $\mathrm{Y}_{2}$ & 0.36 \\
\hline 11 & & $\begin{array}{r}\text { Operators are not card } \\
\text { holders, illegal operations }\end{array}$ & $\mathrm{E}_{1}$ & 0.40 \\
\hline 12 & & Equipment leakage & $\mathrm{E}_{2}$ & 0.32 \\
\hline 13 & & $\begin{array}{l}\text { Pit block reinforcement } \\
\text { is not strong }\end{array}$ & $\mathrm{G}_{1}$ & 0.44 \\
\hline 14 & \multirow[t]{2}{*}{$\begin{array}{l}\text { Site management } \\
(\mathrm{G})\end{array}$} & $\begin{array}{l}\text { The hoisting command } \\
\text { command is not clear }\end{array}$ & $\mathrm{G}_{2}$ & 0.43 \\
\hline 15 & & $\begin{array}{l}\text { Equipment violation } \\
\text { operation }\end{array}$ & $\mathrm{G}_{3}$ & 0.40 \\
\hline
\end{tabular}

Table. 2 Metro construction risk level table

\begin{tabular}{cccccc}
\hline Ourrent level & Level 1 & Level 2 & Level 3 & Level 4 & Level 5 \\
\hline $\mathrm{P}$ & $1 \sim 0.7$ & $0.5 \sim 0.7$ & $0.45 \sim 0.55$ & $0.3 \sim 0.5$ & $0 \sim 0.3$ \\
\hline
\end{tabular}

Bayesian network system. The $\mathrm{BN}$ topology model of $\mathrm{BN}$ analysis software is established for the construction of risk management of deep foundation pit construction of subway station. The BN topology model of BN analysis software is established.In this paper, we use Netica software to build Bayesian network. The corresponding allocation of the risk categories for continuous wall construction is checked for each node. The conditional probability table for node $\mathrm{X}$ can be calculated from model [7].

$$
\mathrm{P}\left(\mathrm{Y} \mid \mathrm{X}_{\mathrm{P}}\right)=1-\prod\left(1-\mathrm{P}_{\mathrm{i}}\right), \mathrm{X}_{\mathrm{i}} \in \mathrm{X}_{\mathrm{n}}
$$

If the conditional probability ratios of known nodes $X_{1}$ and $X_{2}$ are 0.43 and 0.64 respectively, the conditional probability of $\mathrm{X}$ is calculated as follows:

$$
\begin{array}{r}
\mathrm{P}\left(\mathrm{X}=\mathrm{Y} \mid \mathrm{X}_{1}=\mathrm{Y}, \mathrm{X}_{2}=\mathrm{Y}\right)=1-(1-0.43) \times(1-0.64)=0.2052 \\
\mathrm{P}\left(\mathrm{X}=\mathrm{N} \mid \mathrm{X}_{1}=\mathrm{Y}, \mathrm{X}_{2}=\mathrm{Y}\right)=1-0.2052=0.7948
\end{array}
$$

The conditional probability of the $\mathrm{X}$-node is shown in Table 3. 
Table. $3 \mathrm{X}$ node conditional probability table

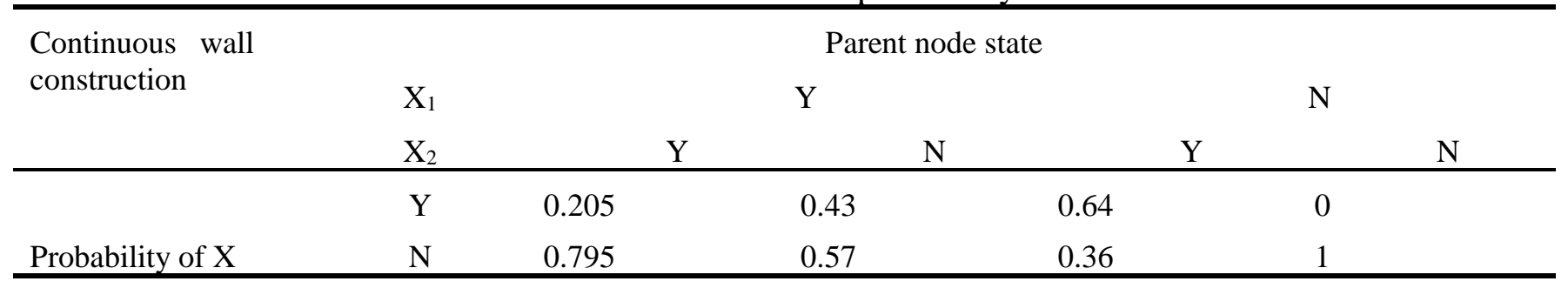

The results obtained are consistent with those of the software in Figure 1. Therefore, the basic data of the previous six categories of risk are input according to the above steps, and the probability of each node edge and the probability of occurrence of leaf nodes can be obtained. After the calculation of the network parameters, the Bayesian model is used to calculate the final result, the six types of risk status and the overall risk level are shown in Table 4.

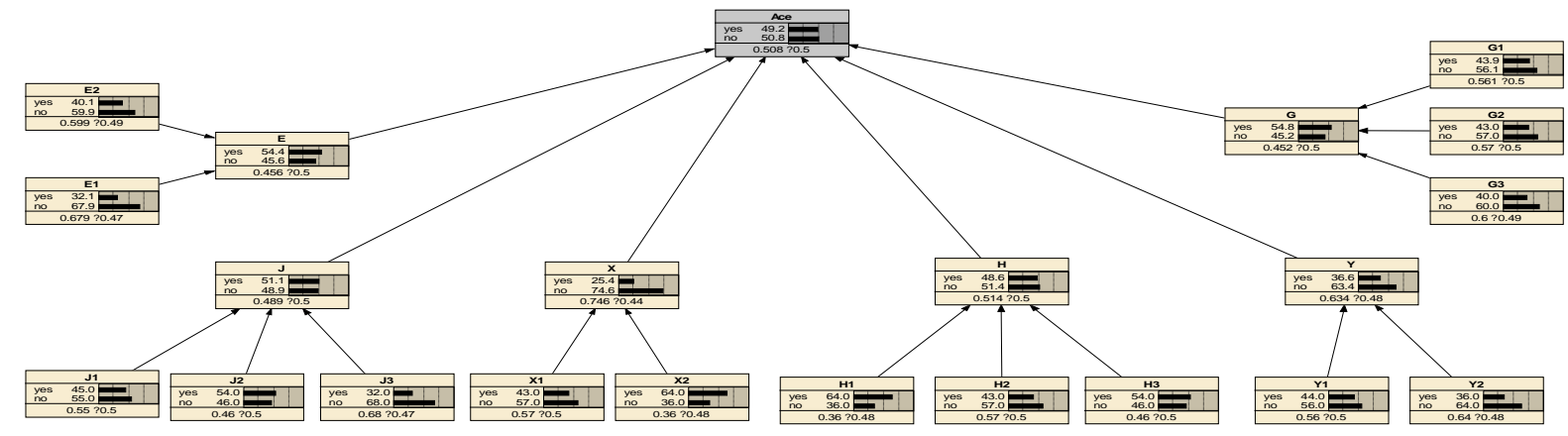

Fig.1 The calculation model of construction project risk probability

Table.4 Six types of risk probability

\begin{tabular}{crrrrrrl}
\hline & $\mathrm{E}$ & $\mathrm{J}$ & $\mathrm{X}$ & $\mathrm{H}$ & $\mathrm{Y}$ & $\mathrm{G}$ & $\mathrm{ACE}$ \\
\hline $\mathrm{Y}$ & $54.6 \%$ & $51 \%$ & $25.4 \%$ & $48.6 \%$ & $36.6 \%$ & $54.8 \%$ & $49.2 \%$ \\
$\mathrm{~N}$ & $45.4 \%$ & $49 \%$ & $74.6 \%$ & $51.4 \%$ & $63.4 \%$ & $45.2 \%$ & $50.8 \%$ \\
\hline
\end{tabular}

Compared to the risk level table 2, the overall risk level is $49.2 \%$, which belongs to the $0.45 \sim 0.55$ interval. It is known that the overall risk possibility is III level.

sensitivity analysis. From Table 1 shows that the risk category contains a total of three major risk factors. In order to explore the effect of $\mathrm{J}_{1}-\mathrm{J}_{3}$ on $\mathrm{J}$, sensitivity analysis of $\mathbf{J}$. Select the $\mathrm{J}$ node to determine the influence degree of $\mathbf{J}$ is $\mathrm{J}_{1}-\mathrm{J}_{3}, \mathrm{~J}$ is how to determine the target node by other nodes affected by sensitivity analysis of the data shown in Table 5.

Table.5 Sensitivity analysis results of risk $\mathbf{J}$

\begin{tabular}{clll}
\hline Node & Variance & $\begin{array}{l}\text { Mutual } \\
\text { Reduction }\end{array}$ & $\begin{array}{l}\text { Variance of } \\
\text { Beliefs }\end{array}$ \\
\hline $\mathrm{J}$ & 0.2494 & 0.9945 & 0.2493945 \\
$\mathrm{~J}_{3}$ & 0.5173 & 0.1684 & 0.5173203 \\
$\mathrm{~J}_{1}$ & 0.02345 & 0.0544 & 0.2345000 \\
$\mathrm{~J}_{2}$ & 0.007845 & 0.0230 & 0.0078452 \\
\hline
\end{tabular}


Table.6 The risk factors of probability and sensitivity ranking table

\begin{tabular}{ccc}
\hline $\begin{array}{c}\text { Risk } \\
\text { category }\end{array}$ & $\begin{array}{c}\text { Risk } \\
\text { probability }\end{array}$ & $\begin{array}{c}\text { Risk factor } \\
\text { sensitivity } \\
\text { ranking }\end{array}$ \\
\hline E & III & $\mathrm{E}_{2}>\mathrm{E}_{1}$ \\
J & III & $\mathrm{J}_{3}>\mathrm{J}_{1}>\mathrm{J}_{2}$ \\
X & IV & $\mathrm{X}_{2}>\mathrm{X}_{1}$ \\
H & IV & $\mathrm{H}_{2}>\mathrm{H}_{1}>\mathrm{H}_{3}$ \\
Y & IV & $\mathrm{Y}_{1}>\mathrm{Y}_{2}$ \\
G & III & $\mathrm{G}_{1}>\mathrm{G}_{2}>\mathrm{J}_{3}$ \\
\hline
\end{tabular}

By comparing the variance reduction between $\mathrm{J}_{1}$ and $\mathrm{J}_{3}$ in Table 5 , we can see the main risk for the excavation, settlement and displacement of surrounding buildings is the most important factor, the risk control of foundation pit excavation is most sensitive.

In order to determine the accuracy of the data, assuming $f$ the factors on the basis of the original probability of occurrence of the same degree (such as 10\%) changes, you can observe the impact of the final edge of the edge of the probability of the sensitivity to determine the size. When $\mathrm{P}\left(\mathrm{J}_{1}=\mathrm{Y}\right)=35 \%, \mathrm{P}(\mathrm{J})=51.2 \%$. Similarly, when $\mathrm{P}\left(\mathrm{J}_{2}=\mathrm{Y}\right)=44 \%, \mathrm{P}(\mathrm{J})=51.1 \%$; when $\mathrm{P}$ $\left(J_{3}=Y\right)=$ when $22 \%, P(J)=49 \%$; which can be drawn to $J$ of the sensitivity analysis results. $J$ on $\mathrm{J}_{3}, \mathrm{~J}_{1}, \mathrm{~J}_{2}$, the sensitivity is reduced in turn. This conclusion is consistent with the conclusion of the above sensitivity analysis, as shown in Table 6.In the construction phase of the risk, the main risk factors investigated, timely treatment can better control risk. At the same time, focusing on the safety risk of the subway construction stage, it is the key to realize the safety risk control of the subway project to compile a complete construction safety risk management manual.

\section{Summary}

Because of the complexity of the construction environment of subway station and instability will lead to many risk factors of production, Bias network is very suitable for the uncertain problem, Bias applied to the subway station network system risk analysis research, the main conclusions are as follows:

Through the collection of literature and expert interviews and discussion in the field of information summarized 15 main risk factors.Finally, the probability of the 6 types of risk in the construction of the subway station is obtained and the overall risk probability is III.

Through the sensitivity analysis, it can accurately analyze the sensitivity of the risk factors in the construction of the subway station. The results show that the most sensitive three types of risk factors are the settlement and displacement of the surrounding buildings during the excavation of the foundation pit. The horizontal displacement of the pier is too large when the light rail is strengthened, and the foundation pit is not fastened or welded.

The main risk factors in the analysis of sensitivity should be taken into account in the project, to strengthen the monitoring of settlement and deformation, and reinforcement .

\section{Acknowledgements}

This work was financially supported by the National Natural Science Foundation of China (51308355), Project supported Liaoning Province, colleges and universities outstanding young 
scholar growth plan (LJQ2014058), Ministry of Housing and Urban-Rural Development of the People's Republic of China Project (2015-K3-025) and Natural Science Foundation of Liaoning Province (20170540736).

\section{References}

[1] S.L.Chen :Chinese Journal of Underground Space and Engineering, Vol. 2 (2006) No.1, p.32.

[2] D.A.Chen. :Safety risk analysis of subway construction based on fault tree(Ph.D., Huazhong University of Science and Technology, China 2011), p.16.

[3] F.W.Li.X.L.Du.:Journal of Beijing University of Technology, Vol. 38 (2006) No.2, p.167.

[4] X.Xin, P.Wan.:Chinese Journal of Geotechnical Engineering ., Vol. 34 (2011) No.5, p.342.

[5] X.G.Wu,B.J.Ding:China Safety Science Journal , Vol. 24 (2014) No.1, p.83.

[6] Z.Ja:Study on construction accident evaluation and comprehensive countermeasures of Shenyang Metro(MS., Dongbei University, China 2011), p.25.

[7] J.G.Zhang:Science and Technology Management Research, Vol. 1 (2006) No.6, p.193. 